\title{
CHICOMEXOCHITL Y EL MAÍZ ENTRE LOS NAHUAS DE CHICONTEPEC: LA CONTINUIDAD DEL RITUAL ${ }^{1}$
}

ABSTRACT The cultivation and veneration of corn is central to all Mesoamerican cultures. Long before the Spaniards arrived indigenous people worshiped corn and pleaded for each harvest to be as good as the preceding one. Today's Nahuas consider corn sacred and never permit it to lie on the ground: it must always be protected and sheltered. The Nahuas of Chicontepec, Veracruz continue to dance and pray to the corn deity, Chicomexochitl "Seven Flower". This paper reveals the continuity of ritual practices and symbolism relating to the worship of maize in Nahua culture from prehispanic times to the present. It is based on the sixteenth-century written sources, recent anthropological studies, and my own fieldwork associated with the Chicomexochitl ritual.

Palabras clave: nahuas, Chicomexochitl, maíz, Chicontepec, ritual

Keywords: Nahuas, Chicomexochitl, corn, Chicontepec, ritual

\footnotetext{
El presente trabajo fue realizado en el marco del Proyecto FOCUS "Encuentros lingüísticos entre el Viejo y Nuevo Mundo” financiado por la Fundación para la Ciencia Polaca (FNP) y realizado bajo la dirección de Dra. Justyna Olko en la Facultad de “Artes Liberales”, Universidad de Varsovia.
} 


\section{INTRODUCCIÓN}

El cultivo y el culto del maíz es fundamental para todas las culturas mesoamericanas. Desde antes de la llegada de los españoles se adoraba al maíz, se le imploraba para que las siguientes cosechas fueran iguales de benéficas. Alfredo López Austin afirma que entre los antiguos nahuas el maíz era indispensable para la vida, ya que la entidad anímica producía el crecimiento del niño y de la facultad de pensamiento ${ }^{2}$. También, para los nahuas de hoy el maíz es sagrado y nunca debe estar tirado en el suelo: siempre deber ser protegido y resguardado. De distintas maneras se le rezaba al maíz, principalmente en la segunda mitad del año, lo cual está bien documentado en las fuentes del siglo XVI. En sus Primeros Memoriales el fray Bernardino de Sahagún reporta que se adoraba a las deidades de maíz llamadas Cinteotl, Xochiquetzal, Tocih, Chicomecoatl, Xochipilli y Xilonen ${ }^{3}$. Por su parte, Durán registra a la diosa con tres nombres: Chicomecoatl, Chalchiuhcihuatl y Xilonen y menciona estas diosas que se ofrecen tratar era las diosas de las mieses y de todo género de simientes y legumbres que esta nación tenía para su sustento ${ }^{4}$. Además agrega que le ponían a la diosa Chicomecoatl mazorcas en el cuello y en las manos ${ }^{5}$, mientras que a Chalchiuhcihuatl le adornaban el cuello con un collar de mazorcas de oro, labradas a manera de mazorcas de maíz. Entonces hay indicios de que se trataba de la misma diosa que tenía distintos nombres, dependiendo del día y de la etapa del ritual en que la veneraban. Considero necesario examinar la relación entre este culto antiguo y su supervivencia en la actualidad. Los nahuas de Chicontepec siguen bailando y rezando a la deidad de maíz llamada Chicomexochitl "Siete Flor".

Tal y como observa López Austin, en el mundo mesoamericano existía una fuerte relación entre las fiestas religiosas y las actividades agrícolas ${ }^{6}$. Se dirigía al maíz como a un ser personalizado que aparecía bajo varios nombres, entre ellos la diosa de maíz tierno, Xilonen, y del maíz maduro, Chicomecoatl. Actualmente los nahuas hablan al maíz como si fuera un niño o niña, esto es, como si fuera un ser humano. En el discurso ritual y cotidiano Conecintli ("Hijo-maíz") es el apelativo que se da al maíz nuevo, al maíz recién cosechado, y cuando está tierno se llama elotzin ("mazorca" o "maíz tierno"). En este trabajo intentaré demostrar tanto la relación entre el culto del maíz prehispánico y el actual, como el simbolismo del ritual relacionado con Chicomexochitl, basándome en los datos del siglo XVI y en los trabajos antropológicos

2 A. López Austin, Cuerpo humano e ideología. Las concepciones de los antiguos nabuas, México 1996, p. 203-247 (Serie Antropológica, 39).

3 Bernardino de Sahagún, Primeros Memoriales, trad. T.D. Sullivan, H.B. Nicholson, Norman 1997, p. 58, 66, 83 (Civilization of the American Indian Series, v. 200, pt. 2).

4 D. Durán, Historia de las Indias de Nueva España e islas de Tierra Firme, ed. A.M. Garibay K., Vol. 1, México 1984, p. 135 (Biblioteca Porrúa, 136-137).

5 Ibid., p. 136-141.

6 A. López Austin, Tamoanchan y Tlalocan, México 1994, p. 201-202 (Sección de Obras de Antropología). 
recientes, así como en mi conocimiento personal como miembro de la cultura nahua contemporánea.

A pesar de que transcurrieron varios siglos desde que se describieron por primera vez los rituales asociados al culto del maíz, estas creencias sobreviven hoy día en las comunidades. Las ceremonias relacionadas con Chicomexochitl que se llevan a cabo en un municipio vecino a Chicontepec han sido descritas por Alan Sandstrom en su libro El maiz es nuestra sangre: cultura e identidad étnica en un pueblo indio azteca contemporáneo. Sandstrom centra su interés en una visión antropológica e intenta desenmarañar algunas expresiones culturales. Hablando de Chicomexochitl, menciona: esto no es algo que los aldeanos puedan articular con claridad y sin ambigüedades, sino más bien una interpretación mía ${ }^{7}$, eso es, presenta su propia explicación y no la perspectiva de los nahuas y la esencia de su cosmovisión centrada en el maíz ${ }^{8}$.

Por otra parte, Félix Báez-Jorge y Arturo Martínez Gómez mencionan que al ocurrir la destrucción del cuerpo sacerdotal mesoamericano y desmantelarse su organización ceremonial, las devociones populares emergieron como alternativas a la cristianización compulsiva, o bien, como mediadores simbólicos que en algunos casos terminaron sincretizándose con las imágenes católicas ${ }^{9}$. Estos estudiosos atestiguan entonces la riqueza cultural y a la complejidad de las prácticas culturales de los nahuas. Sin embargo, los autores mencionados intentan explicar la cosmovisión nahua, sobre todo desde una perspectiva contemporánea, sin tomar en cuenta el grado de la continuidad y la importancia de los trabajos del siglo XVI. Apoyándome en estas fuentes, considero que la cosmovisión nahua de Tepoxteco pertenece a la tradición más amplia mesoamericana y a la vez se encuentra muy arraigada en la región de Chicontepec, Veracruz. Por lo tanto creo que es importante enriquecer los resultados de mi trabajo realizado en la comunidad con los datos coloniales, lo que permite ver la relación fuerte entre el culto del maíz antiguo y contemporáneo. Además quisiera demostrar la continuidad en el pensamiento nahua que se manifiesta en el ritual asociado con Chicomexochit, analizando las fiestas celebradas en la localidad de Tepoxteco dentro de la región conocida como Huasteca veracruzana. Mi hipótesis es que esta supervivencia se debe al hecho de que la iglesia católica entró a esta comunidad muy tarde, o sea en el año 1979. Este dato me parece relevante ya que significa que los habitantes únicamente han estado inmersos en el catolicismo un poco más de 40 años y por tal motivo continúan varias manifestaciones culturales.

A.R. Sandstrom, El maiz es nuestra sangre. Cultura e identidad etnica de un pueblo indio azteca contemporáneo, trad. S.A. Piotrowska, W.H. Klemme, D.L. Oberstar, México 2010, p. 329 (Colección Huasteca).

8 Cabe mencionar que al momento de escribir el presente artículo, Alan y Pamela Sandstrom están trabajando con los investigadores nativohablantes del Instituto de docencia e investigación etnológica de Zacatecas, todos originarios del municipio de Chicontepec, Veracruz, con el fin de llevar a cabo una reinterpretación, desde la perspectiva indígena, de todo lo relacionado con Chicomexochitl.

9 F. Báez-Jorge, A. Gómez Martínez, 'Los equilibrios del cielo y de la tierra. Cosmovisión de los nahuas de Chicontepec', Desacatos, Núm. 5 (2000), p. 79. 


\section{TEPOXTECO, CHICONTEPEC}

La huasteca veracruzana se encuentra ubicada en el noroeste de México, al norte de las costas del golfo de México. La importancia de esta región se debe a las aportaciones económicas, culturales y religiosas de sus pobladores. Desde la antigüedad los nahuas de esta región comparten su territorio con huastecos, tepehuas y otomíes, vecindad que explica las semejanzas en sus creencias y en su cultura material ${ }^{10}$.

El municipio de Chicontepec, con una población de 55,353 habitantes, se encuentra ubicado en la zona norte del estado de Veracruz. La población indígena constituye alrededor de un $65 \%$ del total, y dentro de este porcentaje el $9 \%$ son hablantes monolingües del náhuat ${ }^{11}$. Tepoxteco se localiza a $17 \mathrm{~km}$ de la cabecera municipal y cuenta con 380 habitantes: 195 del sexo masculino y 185 del sexo femenino (según el Centro de Salud de Tepoxteco, 2012). El español está presente como lengua primaria de instrucción en las escuelas en todos sus niveles; además, se habla en la clínica de salud y en otras instancias gubernamentales. Actualmente el idioma náhuatl sólo presenta una gran vitalidad entre los adultos, convirtiéndose en la lengua secundaria de casi todos los habitantes de esta localidad. Los niños y jóvenes ya no utilizan la lengua, habiéndose transformado en hablantes pasivos, por lo cual la lengua tiene un grado de desplazamiento lingüístico considerable frente al español. A pesar de que éstos últimos son hablantes pasivos, se manifiestan de una manera un poco distinta dentro de las prácticas culturales dado que siguen participando en este tipo de actividades tradicionales.

Mapa 1. La Huasteca veracruzana y la localidad de Chicontepec, Ver. México.

(Fuente: archivo muncipal)

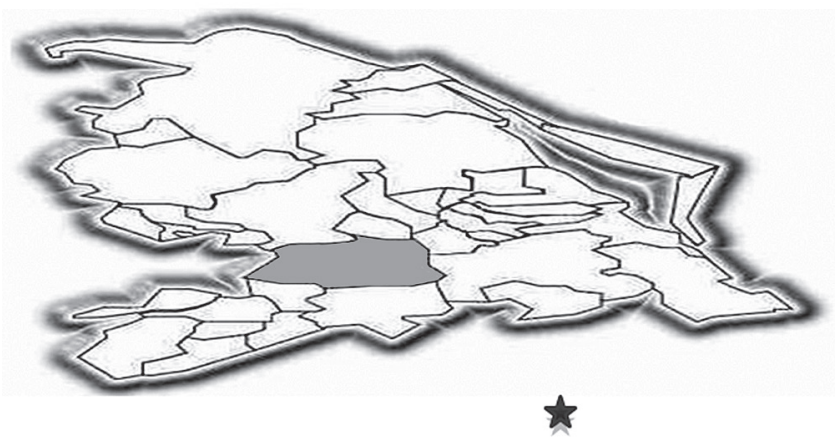

Como mencioné anteriormente, la presencia de la iglesia católica tiene solamente alrededor de 40 años en esta comunidad. Los habitantes mencionan que una de las personas que introdujo el catolicismo en 1979 fue el catequista de otra localidad vecina

\footnotetext{
$10 \quad$ Ibid., p. 80.

11 Instituto Nacional de Estadística y Geografía, México, 2005.
} 
a Tepoxteco ${ }^{12}$. Según la información proporcionada por Fortino de la Cruz, nativohablante y originario de esta localidad en la entrevista conmigo, las personas de esta localidad no asistían porque no sabian que palabra traía, y no mostramos interés. Meses después solamente dos o tres familias llegaron a creer en esa palabra. Actualmente ahora ellos son los catequistas y formaron su grupo y ahora tienen su propia creencia y desprecian cuando nosotros hacemos los rituales.

El dato anterior es sumamente importante ya que refuerza mi hipótesis presentada en este trabajo. Parece significativo que este pueblo, como muchas otras comunidades vecinas, no tenga ningún santo católico propio, lo que contribuyó al hecho de que la mayoría de los pobladores se identifican más con Chicomexochitl. Tomando en cuenta la observación acertada de James Lockhart que un santo era el símbolo principal que identificaba y unificaba a cada entidad sociopolítica, no sólo el altepetl, sino a sus partes constitutivas $^{13}$, creo que la iglesia católica no logró transformar el fundamento tradicional de las prácticas rituales en esta comunidad de estudio.

\section{EL MAÍZ Y SUS DEIDADES}

La deidad de Chicomexochitl constituye una de las expresiones religiosas más importantes en el norte de Veracruz. Según Sandstrom, Chicomexochitl es un héroe cultural mitico que simboliza la importancia central del maiz en la vida nabua ${ }^{14}$. La adoración del maíz y su simbolismo religioso cosmogónico está también presente en los pueblos tének y otomíes que comparten varios elementos del culto, lo cual se debe a su cercanía y la convivencia entre unos y otros. Además, en su trabajo pionero sobre las deidades del maíz prehispánicas, Karl Taube encuentra similitudes relevantes en la mitología y las creencias de los mayas y de los nahuas ${ }^{15}$.

El ritual de Chicomexochitl tiene dos funciones: la primera es el acto de pedir lluvias y buenas cosechas; la segunda es el agradecimiento al maíz y demás productos comestibles. Aunque en las casas particulares se puede ver altares con imágenes católicas (pero también con recortes de papel escondidos detrás de estas imágenes), este supuesto sincretismo religioso no se manifiesta directamente en el ritual del maíz. Es además notable que muchas personas al participar en la ceremonia parecen alejarse de cualquier elemento del culto católico, identificándose todos con el maíz, es decir, con Chicomexochitl.

Para entender el simbolismo del ritual contemporáneo, es oportuno añadir algunos registros del siglo XVI. Por ejemplo, al mencionar las fiestas en honor a Chicomecoatl

12 Juan Martínez, recuerda cuando un catequista de Tepexocoyo llegaba a dar unas pláticas en lengua náhuatl acerca de la iglesia católica.

13 J. Lockhart, Los nabuas después de la conquista. Historia social y cultural de la población indígena del México central, siglos XVI-XVIII, trad. R. Reyes Mazzoni, México 1999, p. 340 (Sección de Obras de Historia).

14 A.R. Sandstrom, El maiz es nuestra sangre..., p. 329.

15 K. Taube, 'The Classic Maya Maize God: A Reappraisal' en V.M. Fields, M.G. Robertson (coord.), Fifth Palenque Round Table 1983. Proceedings of the Fifth Palenque Round Table Conference, June 12-18, 1983, Palenque, Chiapas, Mexico, Vol. 3, San Francisco 1985, p. 7. 
y Tocih, diosas del maíz maduro, Sahagún describe la ofrenda y la siembra simbólica del maíz frente a los participantes de la ceremonia:

- ...oalquiça in inteteupan, oalxinachpixoa: vncan in jtlaquaian diablo, amo cenca vecapan. Aub in tlecoqueh: njman ic qujalchachaiaoa, qujoltetepeoa, qujoalcecenmana tepan, in xinachtli: iztac tlaolli, coztic tlaolli, iavitl, xiubtoctli...

salen de sus templos, siembran las semillas (xinachtli). Ahí, el lugar de la comida del diablo (mesa-altar de Huitzilopochtli), no era muy alto. Cuando subieron inmediatamente escupían, esparcían, dispersaban sobre la gente, las semillas: los granos de maíz blanco, de maíz amarillo, del negro, y los grandes tallos ${ }^{16} \ldots$

En la cita anterior nos enteramos de la ofrenda de tres tipos de colores de maíz y cabe mencionar que estos mismos tipos de maíz son los que se consumen y adoran en la comunidad de estudio: chipahuac, coztic y yahuitl ("blanco", "amarillo" y "negro"). Además, menciona que este ritual se celebraba en el templo y era parte de la ofrenda asociada a la diosa del maíz Chicomecoatl. Por su parte, fray Diego Durán describe el sacrificio de una joven de 13 o 14 años que personificaba a Chicomecoatl justamente en la temporada de cosechas entre septiembre y octubre ${ }^{17}$, lo que corresponde a la celebración actual en Tepoxteco. En el caso de Tepoxteco personifican a Chicomexochitl una pareja de niños entre 10 a 12 años, quienes representan al maíz. Se les entrega un arreglo floral con tres mazorcas amarradas de los tres colores mencionados; también se les entrega un arreglo floral llamado maxochitl "mano-flor". Además se les coloca en el cuello un collar de flores llamado xochicozcatl "collar de flores". La persona encargada en el ritual se llama huehuehtlacatl o "viejo-hombre". Entre sus rezos él menciona que los niños representan al maíz tierno y que éstos tienen que transmitirle las fuerzas al maíz y viceversa para que en el año siguiente haya abundancia de este producto. Constituye una analogía directa tanto del papel de la niña joven que representa a Chicomecoatl en el tiempo de las cosechas xopanmilli (segunda cosecha), como de la personificación de la diosa de maíz tierno llamada Xilonen cuya fiesta en el siglo XVI se celebraba unos meses antes ${ }^{18}$ en la temporada de tonalmilli (primera cosecha). No obstante, los Primeros Memoriales de Sahagún mencionan los rituales asociados a Chicomecoatl en el "templo de maíz" (Centeopan) también en la primera mitad del año, o sea en el mes de buey tozoztli ${ }^{19}$. Estos datos nos demuestran claramente una continuidad de las prácticas religiosas, tal como lo mencionan Báez-Jorge y Gómez Martínez, considerando que Chicomexochitl tiene varios lazos con Chicomecoat ${ }^{20}$. En seguida abordaré el ritual de Chicomexochitl llevado a cabo en la actualidad.

16 Bernardino de Sahagún, The Florentine Codex. General History of the Things of New Spain, trad. Ch.E. Dibble, A.J.O. Anderson, pt. 3. Book 2: The Ceremonies, Santa Fe 1970 (Monographs of the School of American Research, 14), p. 124. (Traducción V. Cruz).

D. Durán, Historia de las Indias..., p. 136-141.

18 Ibid., p. 127.

19 Bernardino de Sahagún, The Florentine Codex..., pt. 3, Book 2, p. 58-59.

20 F. Báez-Jorge, A. Gómez Martínez, 'Los equilibrios del cielo...', p. 94. 


\section{LA ORGANIZACIÓN DEL RITUAL DE CHICOMEXOCHITL Y LA PETICIÓN DE LAS BUENAS COSECHAS}

A Chicomexochitl se le hacen varias peticiones y agradecimientos en el transcurso del año; por el momento nos centraremos únicamente en lo que corresponde con la petición de las buenas cosechas. En primer lugar, el comité organizador reúne todo lo necesario para que la celebración se lleve a cabo en buen tiempo y forma. La comisión permanente está conformada por hombres y mujeres, teniendo presidente, secretario y vocales, también llamados xochitequihuahmeh ("autoridades de las flores"). Estas personas fijan la fecha y todo lo necesario para el ritual. La celebración se realiza principalmente a finales del mes de mayo que es la temporada de la sequía, o sea el tonalmilli ${ }^{21}$. Una vez que se tiene el presupuesto asignado inician el ritual. Las personas llevan varias ofrendas: maíz, chile, piloncillo, leña y sal, entre otras cosas. Este ritual se lleva a cabo en cuatro días. Los dos primeros días el huehuehtlacatl elabora distintos recortes de papel llamados tlatecmeh hechos de iztacamatl ("papel blanco") que posteriormente serán llamados deidades. La casa de Chicomexochitl se llama Xochicalli "la casa de las flores". Durante la fiesta se toca música llamada xochitlatzotzontli o xochizonez $z^{22}$ ("música de las flores"). Se utilizan los instrumentos de cuerda: violín, jarana y guitarra guapanguera. Los últimos dos días llegan familias completas para participar en el ritual. Los hombres ayudan en la elaboración de distintos arreglos florales, incluyendo xochicozcatl, maxochitl, acatl, poloco ("collar de flores", "flor de la mano", "carrizo", "poloco") ${ }^{23}$; las mujeres ayudan en la preparación de la comida, matando pollos, y haciendo tortillas, tamales, atole, entre otras cosas. Cuatro o cinco veces durante el día dejan sus trabajos designados para bailar algunos sones. En toda la ceremonia se utilizan incienso de copal y flores de temporada. Un acto ritual importante que se realiza durante el tercer día se conoce como quitlaquentiah Chicomexochitl ("visten a Chicomexochitl"). En esta parte de la ceremonia ponen vestimenta a los recortes de papel: cuatro de hombres y tres de mujeres $^{24}$. La ropa nueva con la cual atavían a los recortes incluye blusas, huaraches, aretes y soguillas asociados con la deidad femenina, y sobreros, pantalones, camisas y huaraches para las deidades masculinas. Una vez vestidos los recortes se convierten en deidades del maíz. Se cree que Chicomexochitl es tanto de sexo masculino como de femenino

21 Xopanmilli se refiere a la segunda temporada de siembra de maíz, la cual se realiza en la temporada de lluvias, entre junio a diciembre; tonalmilli es la primera temporada de siembra, la cual se lleva a cabo durante los meses de calor entre enero y mayo.

22 A.R. Sandstrom, El maiz es nuestra sangre..., p. 366.

23 Maxochitl, arreglo floral hecho de los tallos de las hojas de coyol; tiene cinco puntas en donde se insertan flores y queda como una mano; acatl, un tipo de adorno floral hecho de carrizo; poloco es un adorno hecho de una vara tallada con un machete para sacar tiras que forman siete bolitas rizadas, las cuales posteriormente se pintan con un tinte natural de color morado.

24 Según el testimonio del Códice Florentino durante el Ochpaniztli el maíz era decorado con papel y envuelto en una manta (tilmahtli). Actualmente se le adorna con un pañuelo, recortes de papel y flores. Bernardino de Sahagún, The Florentine Codex..., pt. 3. Book 2, p. 124-125. 
y por esa razón el maíz es vestido tanto como hombre como de mujer. Henry B. Nicholson observa que el nombre Cinteotl era frecuentemente empleado como un término genérico de la deidad de maíz en sus aspectos masculino y femenino ${ }^{25}$.

Frente al altar bailan hombres y mujeres, haciendo giros de derecha a izquierda y viceversa, con ofrendas en las manos, hombros y cabezas, que entregan a la deidad. En los pasillos algunas personas hacen arreglos florales, decorando las tallos de maíz. Otras personas ayudan en la elaboración de un altar junto a la puerta principal, y todavía otras participan en la construcción de un arco de flores en el altar mayor. Al realizar estos trabajos muchos platican sobre cosas relacionadas con el campo, tales como el ciclo agrícola, el cultivo del maíz y las herbicidas que dañan la tierra. Hablan también con sus hijos sobre la importancia del culto de Chicomexochitl.

Imagen 1. Regalos entregados a las deidades tanto malignas como benignas: comida, flores, un pollo pequeño y cigarros (fotografía VCC)

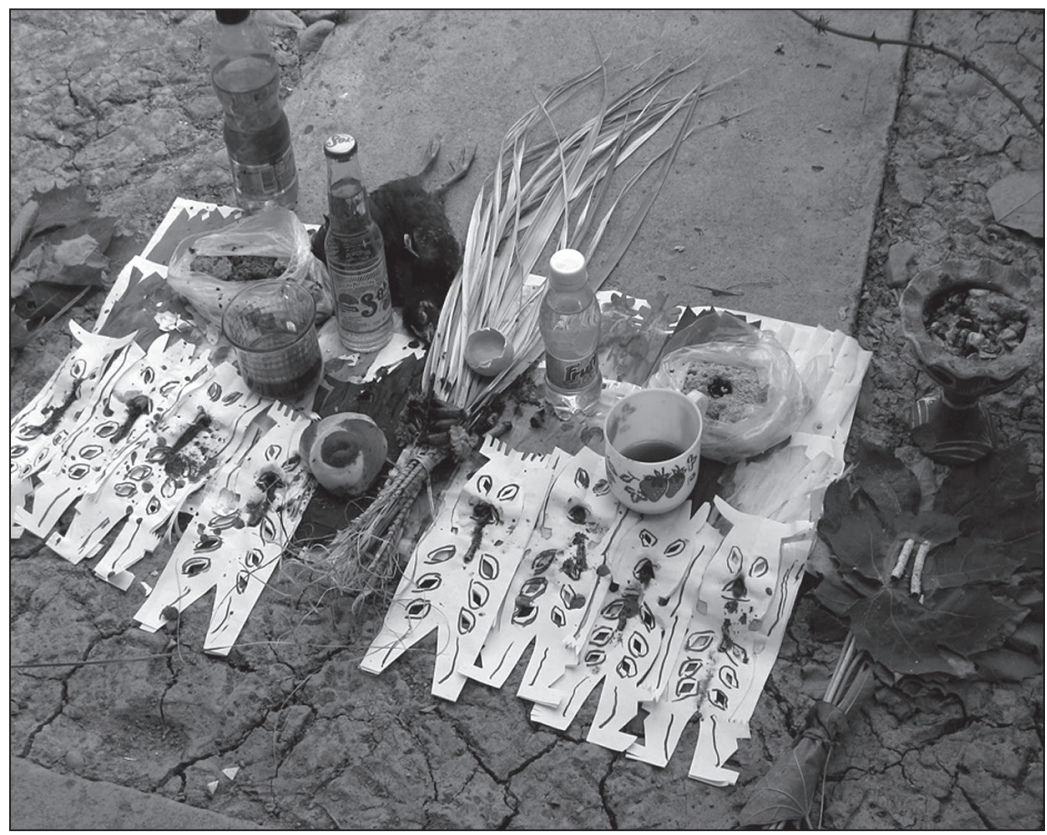

En el cuarto día todos los participantes se preparan para venerar a sus deidades en el cerro. Desde muy temprano se levantan y no comen nada, lo cual significa que ascenderán al cerro en ayunas (mozahuah, "ayunan"). Enseguida todos se ponen a bailar, mientras que el huebuehtlacatl hace sus súplicas a las deidades para poder llegar bien a los cerros, refugio o morada de las deidades. Antes de partir al cerro, todas las

25 H.B. Nicholson, 'Religion in Pre-hispanic Central México' en R. Wauchope, G.F. Ekholm, I. Bernal (ed.), Handbook of Middle American Indians, Vol. 10: Archeology of Northern Mesoamerica, pt. 1, Austin 1971, p. 417. 
personas se limpian: se meten dentro del aro de bejuco con espinas llamado huitzmecatl ("bejuco con espinas") para purificarse antes de llegar a la morada de las deidades $^{26}$. En este mismo sitio se sacrifican uno o dos pollos, justo enfrente de la casa. El huehuebtlacatl limpia el lugar con dos racimos de hojas de tzitzicaztli ("tipo de ortiga") y teotzitzicaztli ("ortiga de dios"). Con estas ramas golpea la tierra y los horcones de la casa para que las entidades malignas se muevan o se quiten del lugar. Esta parte del ritual también es conocida como ochpaniztli "barrida" (más adelante abordaremos este tema). Además, en el mismo lugar se colocan unos recortes de papel de color blanco. En la boca de éstas se introduce un cigarro con el fin de ahuyentar a las entidades malignas y así permitir pasar a la gente sin que éstas le hagan algún daño. Se les ofrenda también flores de coyol, comida y aguardiente, entre otras cosas (ver imagen 1).

\section{EL ASCENSO AL CERRO}

Cuando todas las personas llegan al cerro, el huehuehtlacatl tira unos cigarros prendidos y quema suficiente copal para purificar el lugar. Los participantes cuelgan una manta blanca sobre el sendero al pie del cerro. Pasan por debajo, rozando su cuerpo en ella, y de esta manera terminan el proceso de purificación. Hacen una reverencia y siguen adelante hacia la morada de las deidades. Llegando a la primera mesa sacrifican inmediatamente dos pollos negros. Los músicos amenizan la celebración con los sones adecuados para este lugar y todos se ponen a bailar. Colocan varios recortes de papel llamados petlaxochitl ("flores de estera") y sacrifican un pollo salpicando su sangre sobre el papel. Este acto se llama tlaezhuiah ("tirar la sangre"), pero es también conocido como tlaezpoloah ("manchar con la sangre"). Enseguida ponen racimos de flores de coyol y sobre ellas colocan suficiente comida para saciar a los dioses y guardianes de la naturaleza. Ofrecen además pan, atole, camote, flores, refresco, plátanos, comida de pollo y aguardiente. Al mismo tiempo el huehuehtlacatl hace una purificación conocida como tlacotontli "cosa cortada" con varios racimos de hierbas y recortes de distintos colores. El significado de este acto es limpiar toda entidad negativa cerca del altar: arriba, abajo, a los costados y por la parte de afuera. Rezando y bailando, pide el permiso de las deidades para poder entrar a su casa, y les dirige unas plegarias para que reciban la comida.

En el segundo altar, que se encuentra justo en la mitad del cerro, se sacrifica un pollo para honrar una deidad femenina conocida como Cihuamichin "sirena" o Apanchaneh $^{27}$ ("dueño o dueña del agua") que está asociada con el agua. Cabe mencionar que en la tradición nahua prehispánica las diosas acuáticas estaban vinculadas con las cuevas ${ }^{28}$. Según la tradición oral, Apanchaneh vivió en la localidad de Xoquixhual y dado que

26 F. Báez-Jorge, A. Gómez Martínez, 'Los equilibrios del cielo...', p. 57.

27 A. R. Sandstrom, El maiz es nuestra sangre..., p. 333.

28 A. López Austin, Tamoanchan y Tlalocan..., p. 145. 
sus hermanos no la quisieron, se fue a vivir en el cerro de Postectitlan ${ }^{29}$. A esta deidad también se le identifica como productora de la sal ${ }^{30}$. Justamente muy cerca del altar que se encuentra a la mitad del cerro brota agua salada. En este manantial se coloca comida con bastante sal. En este lugar se les hace una purificación a las mujeres jóvenes, ya que son ellas quienes darán a luz en los próximos años; a las niñas únicamente se les hace una limpia muy sencilla. También se hace un rezo especial a los infantes fallecidos recientemente. En este lugar los músicos tocan unos sones especiales y todos los presentes bailan al ritmo de la música. El huehuehtlacatl formula su pedimento para ascender y sin ninguna intervención negativa llegar a la cima del cerro.

Imagen 2. Un pollo blanco enterrado constituye una forma de agradecimiento a la madre tierra, a la cual también se le entregan flores, refrescos, cervezas y velas (fotografía VCC)

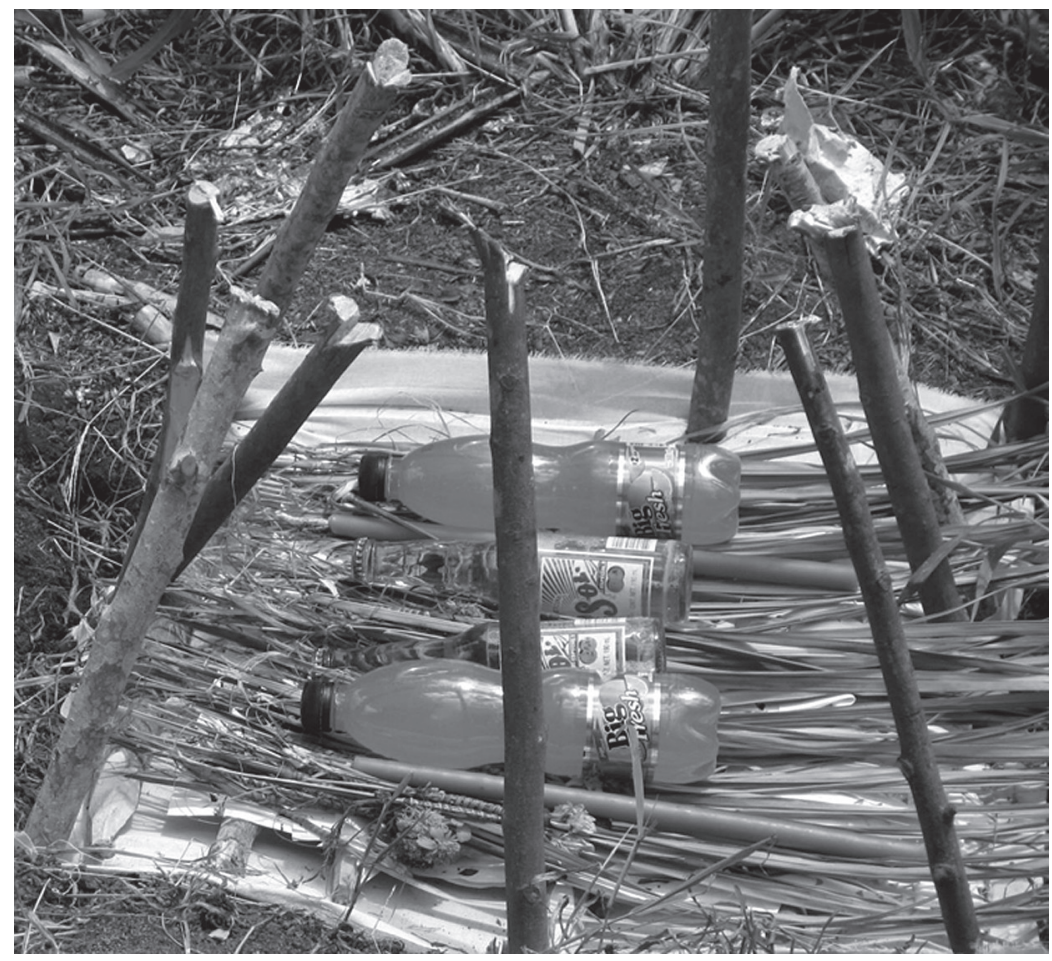

Cuatro horas después alcanzan la parte superior del cerro referido como tepeixco ("la cima del cerro"). Al llegar, todos los participantes hacen una reverencia inclinando la frente ante el hueyi tlaixpamitl ("altar mayor"). El huehuehtlacatl agradece el estar en este punto y salpica aguardiente en casi todo el lugar. Los músicos tocan las melodías adecuadas para el momento crucial de la ceremonia de Chicomexochitl, asociada con la petición de lluvias, mientras que los hombres y las mujeres bailan sin

29 Comunicación personal de Lino Martínez.

30 Comunicación personal de Fortino de la Cruz. 
cesar. Todos los niños y las niñas se colocan a los costados del altar mayor. A pesar del calor sofocante del día, llevan las ofrendas en sus espaldas, cabezas y hombros, solicitando lluvias y buenas cosechas, y pidiendo que el año transcurra sin ningún acontecimiento negativo.

Después de agradecer a los dioses se entierra un pollo vivo de color blanco justo en el centro de la cima del cerro. Los nahuas dicen que se da a comer a tohueyinanan tlalli ("la madre tierra") por los meses transcurridos. Una vez que se introduzca el pollo en el agujero, éste se sella con una sábana blanca, la cual se fija a la tierra con estacas de carrizo y palos. Encima de la sábana se pone bastante comida y demás ofrendas (ver imagen 2).

Después todos se reúnen delante del altar principal. Allí una pareja (hombre y mujer) bailan, cada quien con un pollo en los brazos, a los cuales se les da de beber aguardiente. Posteriormente son sacrificados. Durante el acto del derramamiento de la sangre a los pollos se les tuerce el cuello. También se sacrifica a un guajolote de color negro. En distintos momentos el huehuebtlacatl da unos golpes a la tierra con el bastón diciendo: Nican tiitztoqueh, nican timitzmactialiah nochi tlen moaxca ("Aquí estamos, aquí te entregamos todo lo que es de tu propiedad"). Enseguida se hace una ofrenda a la deidad del sol.

\section{LA ADORACIÓN AL SOL}

Otro punto crucial del ritual es la adoración del sol. Para este acto primero se entierra en el centro del cerro un palo conocido como el palo volador (petlacotl) ${ }^{31}$, el cual está asociado fuertemente con la fertilidad. El huehuehtlacatl purifica ritualmente el palo colgando varios recortes de papel de las deidades conocidas como guardianes de la naturaleza. En la cima de este palo se coloca una especie de canasta llamada buililli, y encima de ella se pone una sábana hecha de papel blanco (iztacamatl). Se sacrifica un pollo negro y se vierte su sangre sobre los recortes. Se ofrenda bastante comida, frutas de temporada, aguardiente, tamales, refrescos, atole y flores de coyol, que con sus puntas colgando hacia afuera de la canasta simbolizan los rayos del sol. Además se amarran cuatro listones que simbolizan los cuatro puntos cardinales: campa huallaub tonatiuh, campa huetzi tonatiuh, campa huallaub ehecatl huan mictlanpa "este, oeste, norte y sur". Enseguida los participantes amarran en la canasta cuatro pequeños pollos vivos con sus cabezas hacia abajo. En mi opinión el simbolismo de este acto se vincula con el descenso de los dioses, representados como aves, a la tierra como portadores de mensajes divinos. A la vez están fuertemente asociados con la fertilidad y las lluvias. Un ritual parecido sobrevive en la cultura totonaca: cuatro hombres ataviados descienden del palo con los brazos extendidos como si fueran aves. Creo que ambas formas de este rito compar-

31 J. Bierhorst, A Nahuatl-English Dictionary and Concordance to the Cantares Mexicanos, with an Analytic Transcription and Grammatical Notes, Stanford 1985, p. 264-265. Sobre el término petlacotl nos dice: árbol artificial ricamente decorado de plumas evidentemente considerado el emblema del espíritu divino, agrega también, que en México este árbol es todavía utilizado con los danzantes actuales. 
ten mucho de su significado simbólico. Los nahuas de Tepoxteco dejan morir a los pollos amarrados como ofrenda a la deidad del sol, Tonatiuh (ver imagen 3). Además, en la cima del cerro un hombre y una mujer, representan los papeles de la pareja divina que simboliza la fertilidad, y depositan allí cuadro granos de maíz de distintos colores para que estas mismas deidades en cuatro días la germinen. Cabe aclarar que el significado de este rito no se limita a la germinación del maíz, sino que alude a la procreación de un nuevo ser. Así, el maíz sirve como un medio para la obtención de la vida: el acto de nacer es posible a través de la deidad mayor, Chicomexochitl. Este concepto religioso tiene raíces muy profundas en el mundo nahua. Tal como observó López Austin, desde los tiempo prehispánicos los nahuas identificaban el ciclo de la vida y la circulación de las entidades anímicas con el ciclo del cultivo de maíz y la circulación de sus esencias, las fuerzas de crecimiento ${ }^{32}$.

Una vez realizada la petición de las buenas cosechas en el cerro, la gente regresa a la casa xochicalli. Todos juntos brindan con refresco y aguardiente enfrente del altar para que el acto llevado a cabo traiga bienestar a toda la comunidad y a la región. Finalmente todas las personas regresan a sus casas. Ahora centraremos nuestra atención en el ritual del maíz.

Imagen 3. La ofrenda a Tonatiuh, con pollos amarrados de las patas con la cabeza hacia abajo (fotografía VCC)

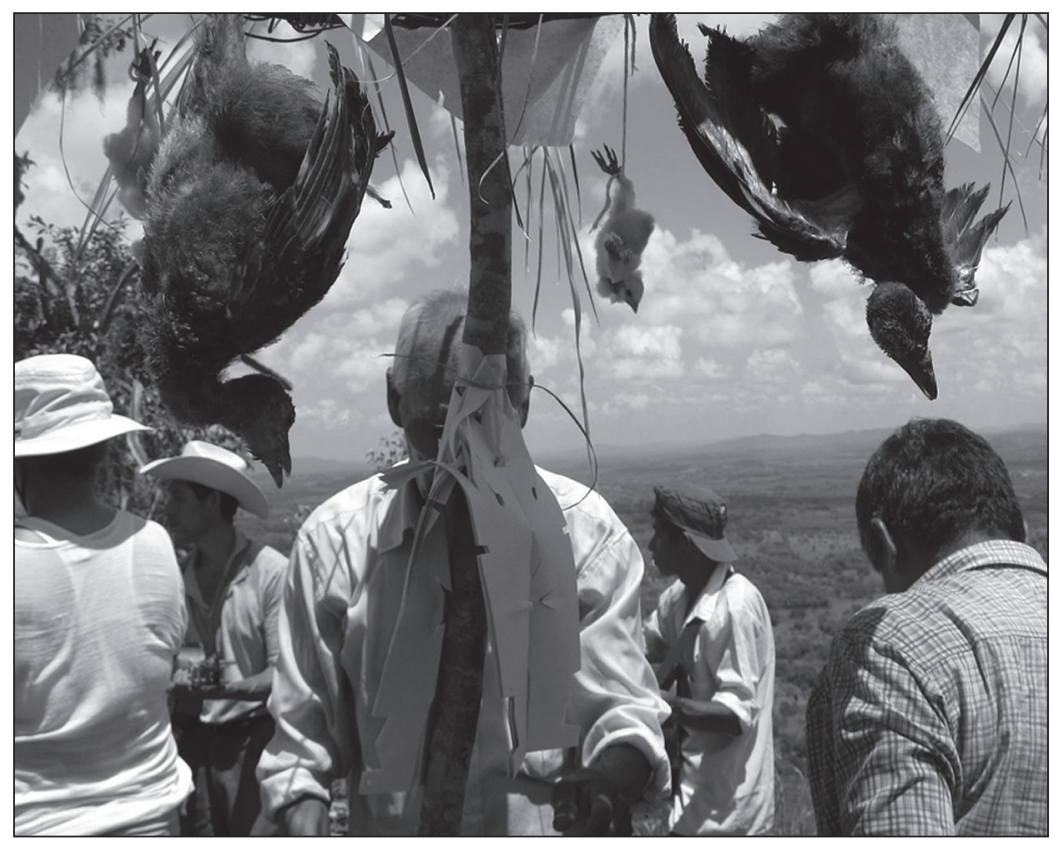

32 A. López Austin, Tamoanchan y Tlalocan..., p. 209-211. 


\section{CHICOMEXOCHITL COMO LA DEIDAD DE MAÍZ DENTRO DE LA TRADICIÓN ORAL}

Todo inicia cuando una persona iba por el bosque y de repente vio un destello a su paso, como si los rayos del sol iluminaran solamente ese punto. Así nos narra el buehuehtlacatl de la localidad de Chapixtla. El grano de maíz estaba perdido en el bosque y una persona lo levantó y se lo llevó a su casa con el fin de esconderlo. Lo enterró y de ahí germinó el maíz. Unos meses después ya tenía las primeras dos mazorcas y como no sabía que hacer con ellas, las guardó y siguió sembrando la semilla (xinachtli). Cuando ya tenía su casa llena de maíz, empezó a repartirla entre todos los miembros de la comunidad. Algunas personas recibieron costales de maíz, a otras les tocó solamente algunas mazorcas de distintos colores, y las últimas personas únicamente obtuvieron siete jícaras llenas de maíz. Los lugareños empezaron a asociar al maíz con el número siete debido a que fueron siete los últimos ancianos que recibieron siete jícaras llenas de maíz. Además, se dice que estos ancianos provenían de Chicontepec y de ahí se originó el nombre ("en el lugar de siete cerros").

En la tradición oral también se asocia Chicomexochitl con un niño travieso que vivía con su abuela malvada llamada tenantzitzimitl. Ella no lo quería porque era muy audaz: domaba a todos los animales feroces y no le hacían ningún daño; convertía a las fieras en sus amigos. Chicomexochitl no se sentía querido por su familiares por lo que decidió irse a vivir en el monte. Semanas después, cuando el pueblo se quedó sin fuego y sin alimento, sus habitantes se dieron cuenta de la importancia de esta deidad. Así que fueron por él con música y flores al monte donde estaba perdido. Se dice que solamente si se le venera a esta deidad, podrá comer el pueblo y siempre habrá maíz y buenas cosechas.

Los habitantes de Tepoxteco y de las comunidades vecinas siembran el maíz con la coa llamada en náhuatl cuatlatoctli o cuabuitzoctli y no utilizan el sistema de barbecho. En el momento de la siembra del maíz hacen una oración en el centro de la milpa y recogen tierra del sus cuatro esquinas para que sea una buena cosecha. También le entregan comida a la tierra y al maíz, encendiendo una vela y rompiendo un huevo. Durante la siembra del maíz se pone cuatro semillas en cada agujero, lo cual apunta a los cuatro rumbos de la tierra: xopantlan 'norte', miccaohtli 'sur', ihuetzca tonatiuh, 'oeste' y tonalixpan 'este' 33 .

\section{EL AGRADECIMIENTO AL MAÍZ}

El ritual de agradecimiento al maíz se llama elotlamanaliztli, o "la fiesta de la mazorca" 34 . Esta celebración se realiza a finales de septiembre o a inicios de octubre como expresión

33 F. Báez-Jorge y A. Gómez Martínez ('Los equilibrios del cielo..., p. 83) mencionan que Los puntos cardinales pueden variar un tanto, dependerá de quién sea el elicitado...

34 A.R. Sandstrom (El maiz es nuestra sangre..., p. 374) menciona que el ritual se organiza en espera de 
de gratitud a la tierra por hacer germinar y crecer el maíz, y, a la vez, por alimentar a los habitantes. De igual manera el huehuehtlacatl es la persona quien encabeza la ceremonia, con la diferencia de que durante este ritual ya no se sube al cerro, sino que todo se celebra en el Xochicalli (la casa de Chicomexochitl) ${ }^{35}$. De la misma manera que para la petición de lluvias y de buenas cosechas, esta ceremonia se lleva a cabo durante cuatro días después de terminar con todos los preparativos necesarios.

Habiendo reunido todos los recortes de papel, el huebuebtlacatl realiza la primera limpia, pidiendo permiso y a la vez agradeciendo a Tlitl Xihuantzin, Pilatzin y Tonatiuh («fuego Xihuantzin, agua y sol») por haber producido las mazorcas. Moviéndose a cada uno de los puntos antes mencionados, hace rezos y les entrega a los recortes flores y comida. También se elaboran los arreglos florales de poloco, maxochitl y xochicozcatl.

Imagen 4. Elotzacualli ("pirámide o montículo de mazorcas"). Los participantes le entregan al maíz todo tipo de comida y bebida en la celebración de elotlamanaliztli "la fiesta de mazorcas" en Lomas del Dorado, Veracruz (fotografía de Noemí Fernández)

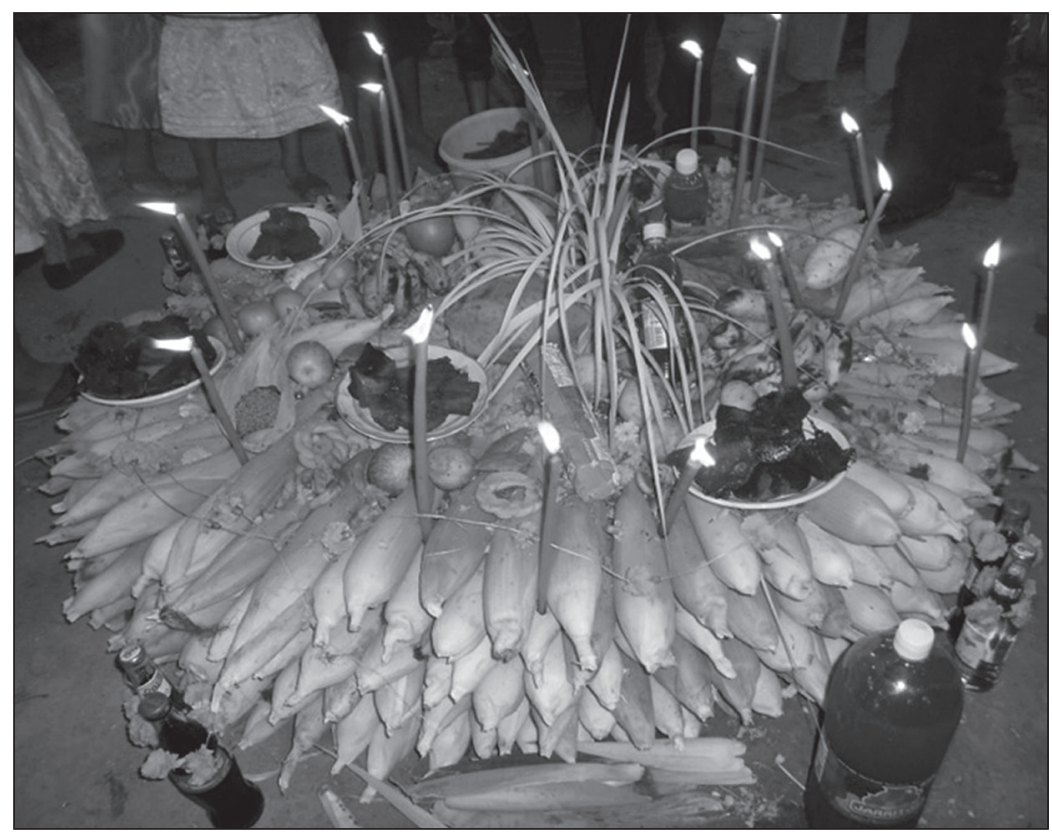

Antes de entrar a la casa de Chicomexochitl los hombres y las mujeres bailan alrededor de la casa con la música tradicional llamada xochitlatzotzontli o xochizonez. Los hombres danzan con los tallos de la mazorca con espigas, y las mujeres llevan el arreglo floral que está hecho de tres plantas de maíz completamente decoradas. Uno de los

la siembra de primavera. Sin embargo, únicamente me estoy enfocando el ritual que se hace a finales del mes de semptimbre o a principios de octubre.

35 A.R. Sandstrom (ibid., p. 381) menciona que esta celebración ritual puede ser bastante elaborada y costosa. 
hombres baila con un tallo del maíz sin la espiga y sin hojas, únicamente con la mazorca Este tallo, llamado icnotzin o nonotzin ("huerfanito" o "mudito"), alude al abandono del maíz y significa que no puede estar sólo y aislado. Después del baile las personas entran a la casa de la deidad y ponen su mazorca decorado delante del altar. Habiendo reunido todos los morrales y costales de mazorcas, hacen un montículo llamado elotzacualli ("pirámide de mazorcas") lo que en mi opinión simboliza un cerro o una pirámide circular (ver imagen 4). En la imagen podemos observar la comida colocada encima de las mazorcas y algunas velas que simbolizan la luz que dio origen al maíz. También le colocan un collar de flores de cempobualxochitl que simboliza la unión de los tres tipos de maíz que se producen en la región: blanco, amarillo y negro. Además se ven flores, refresco, cerveza y pan, entre otros productos. Hombres y mujeres se ponen a bailar alrededor del montículo. También se coloca un racimo de flores de coyol en su centro como símbolo de los rayos del sol.

Finalmente, en esta ceremonia dos personas hacen beber refresco a unos pollos para posteriormente sacrificarlos. Rocían su sangre directamente sobre la tierra en un acto de agradecimiento.

\section{OCHPANIZTLI}

Según los datos de la época colonial uno de los rituales más importantes celebrados por los mexicas en Tenochtitlan en el periodo correspondiente con la segunda semana de septiembre era ochpaniztli ("la barrida") ${ }^{36}$. Esta fiesta coincidía entonces con la temporada de cosechas cuando se hacía el agradecimiento a las deidades de maíz. Por su parte, los nahuas de Chicontepec emplean el mismo nombre para su ritual llevado a cabo en varios lugares y para varios propósitos, todos relacionados con el fin de asegurar la salud y el bienestar en todos los aspectos de la vida. El ochpaniztli tiene lugar también dentro de la ceremonia de elotlamanaliztli que incluye un ritual dedicado a los infantes, el elopehpenaliztli ("levantamiento de la mazorca"). En esta parte de la ceremonia se purifica a todos los infantes nacidos en el año y a los enfermos, pidiendo que les dé fuerzas la mazorca recién producida. Se les busca también un padrino y una madrina (tionan y tiotah) para que sirvan de apoyo en la educación y en el aprendizaje de buenas prácticas culturales. Tanto los padres del niño como los padrinos traen una vela en la mano, mientras que el huebhuetlacatl les hace una "barrida" a los niños con una mazorca con caña, suplicando la mejoría del infante. El fin ritual del ochpaniztli consiste entonces en purificar a los niños dentro el ritual más amplio dedicado al maíz, asegurándoles la salud y las fuerzas para el crecimiento.

Llama la atención que la importante fiesta agrícola de los mexicas en la cual se celebraba buenas cosechas y el nacimiento del dios de maíz, Cinteot ${ }^{37}$, corresponde en cuanto a su ubicación en el ciclo agrario con el ochpaniztli celebrado en Tepoxteco, el cual está

36 D. Durán, Historia..., p. 275-276; Bernardino de Sahagún, Primeros Memoriales..., p. 62-63.

37 J. Olko, 'Hierogamy in the Aztec Ritual', Estudios Latinoamericanos, Vol. 19 (1999), p. 106-107. 
asociado con el recibimiento de la mazorca. A pesar de las diferencias importantes entre las dos fiestas, separadas por cinco siglos y asociadas con regiones diferentes del mundo nahua, existen varios lazos referidos a la construcción, al simbolismo y a los conceptos religiosos manifiestos en ambos rituales, sobre todo la creencia en un vínculo fuerte entre el ciclo de maíz y la vida humana basado en la circulación de esencias espirituales ${ }^{38}$.

\section{EL PAPEL DEL HUEHUEHTLACATL}

Como vimos, el huehuebtlacatl, también conocido como tepahtihquetl "el curandero" o ixtlamatiquetl ("hombre con conocimiento o sabio") desempeña un papel fundamental en la serie de rituales que conforman la fiesta de Chicomexochit ${ }^{39}$. Es un hombre de mucho respeto y con conocimiento profundo de todos los procesos rituales. Siempre es una persona de edad avanzada, seria, muy reconocida en la región como un verdadero conocedor de la naturaleza, y un experto en darle continuidad al pensamiento náhuatl y al simbolismo religioso en la cosmovisión de la cultura nativa. Implora a sus dioses y habla con ellos precisamente porque tiene la capacidad de realizar este tipo de comunicación. Siempre muestra el bastón de mando, actuando como si fuera el gobernante en la tierra.

Sin lugar a dudas, los huehuehtlacameh cumplen un papel fundamental en la lengua y la cultura. Son personajes que intentan mostrar una cultura milenaria, que mediante sueños y visiones recibieron el don de hacer, rehacer y continuar las prácticas culturales. Su profesión es bastante completa: los ixtlamatinih preparan las figurillas de papel, maíz y flores para posteriormente convertirlas en deidades. Por lo tanto, durante todos los rituales, incluyendo la fiesta de Chicomexochitl, elaboran cientos de recortes de diferentes tamaños y colores ${ }^{40}$. Hacen también adornos florales, utilizando las hojas del tipo de palmera conocida como coyolli, tzitzicaztli y flores de cempohualxochitl. Un adorno siempre presente en todos los rituales es el ya mencionado xochicozcatl, que muestra el camino a las deidades tanto malignas como benignas así como a las almas de los difuntos. Además, les muestra el camino de la entrada y la salida de su antigua casa. Los huehuehtlacameh preparan también un arreglo floral llamado maxochitl, que según los habitantes es dedicado a la deidad Macuilxochitl ("Cinco flor").

El siguiente rezo nos ofrece una mirada a la manera en la cual los nahuas de Chicontepec adoran a sus deidades. Julián Martínez dedica su oración a cuatro deidades importantes para la cultura nahua: el sol, el maíz, la tierra y el fuego. Además, dentro de este discurso ritual, podemos apreciar la riqueza de los paralelismos semánticos y gramaticales.

38 T.L. Grigsby y C. Cook de Leonard estudian las similitudes entre el ciclo agrícola-ritual de los nahuas de Tepoztlán en Morelos y el que se describe en el Códice Florentino en 'Xilonen in Tepoztlán: A Comparison of Tepoztecan and Aztec Agrarian Ritual Schedules', Ethnohistory, Vol. 39, Núm. 2 (1992), p. 108-147, en <http://dx.doi.org/10.2307/482390>.

39 F. Báez-Jorge, A. Gómez Martínez, 'Los equilibrios del cielo...', p. 55.

40 A.R. Sandstrom, El maiz es nuestra sangre..., p. 345-366. 
Tonatiuh

Ipan ni tlaltepactli tiitztoqueh.

Ticnequih xicchicahua ni toconeuh, ma cualli moyoltetili.

Nicnequi cualli xicpalehui, xiyolchicahua ni xochiconetzin.

Nican ximonechcahui xihuantzin.

\section{Cintzin}

Nican timitzcamahuiah, nican timitzilhuiquixtiah, nican timitztzahtziliah.

Moconeuh quichihualtia, nican tlaihyohuia.

Xiyoltetili, xiyolchicahua.

Xicmactili itonal.

Tonanan tlalli,

Nican titlachixtoqueh, nican tiixtlapanqueh,

huan nican titlaihyohuihticateh.

Naman nican itztoc mochamanca.

Mitztemoa, mitztlachilticah,

quinequi mocualtlaliz.

Moconehuan mitztemoah.

\section{Xihuantzin}

Naman, Xihuantzin, timitzmactiliah ica yani tipanoz mohmoztlah, tohueyitatah mitzceliz,

Ni tlitl ica yani tipanoz.

Tictlaliah moauh, tictlaliah mopapa, tictlaliah mochichiquil, tictlaliah mocantelah, tictlaliah moyoyon, nican nochi ahcitoc tictlaliah.
El sol

En este mundo estamos.

Queremos que fortalezcas a este hijo nuestro, que se fortalezca muy bien.

Quiero que ayudes,

y que fortalezcas a este niño-flor.

Acércate aquí Xihuantzin.

El maíz

Aquí te hablamos, aquí te festejamos, aquí te imploramos. Tu hijo está enfermo, aquí sufre.

Fortalécelo, fortalécelo.

Entrégale su espíritu.

La madre tierra

Aquí estamos viviendo, de aquí brotamos,

y aquí estamos sufriendo.

Ahora aquí esta tu retoño.

Te busca, te está observando, quiere mejorarse.

Tus hijos te buscan.

El fuego Xihuantzin

Ahora, Xihuantzin, te entregamos estas cosas que diario te harán falta y con las que nuestro gran padre te recibirá.

Te hará falta este fuego.

Ponemos tu agua, ponemos tus tortillas, ponemos tus tamales, ponemos tus velas, ponemos tu ropa,

Aquí ponemos todo completo.

\section{CONSIDERACIONES FINALES}

Como pudimos ver, los nahuas de Tepoxteco, Chicontepec, celebran sus rituales del maíz conservando varias similitudes con el culto y las fiestas religiosas documentadas en las fuentes del siglo XVI. La pregunta que surge es ęcómo, a pesar de tantos años, los nahuas han podido mantener estas prácticas culturales con toda su complejidad y riqueza?

La adoración de agua como Apanchaneh, de la sirena como Cihuamichin, del fuego como Tlitl Xihuantzin, del sol como Tonatiuh, y del viento como Ehecatl corresponden a los cultos fundamentales de las culturas mesoamericanas. Las prácticas rituales de la región de Chicontepec y de otras aledañas atestiguan la supervivencia de los antiguos conceptos de los nahuas, los cuales se manifiestan muy fuertemente en las ceremonias 
asociadas con Chicomexochitl, la deidad que se asemeja mucho a la antigua Chicomecoatl, o con Cintzin, la que evoca a Cinteotl y a Xochipilli. En vista de esta continuidad fuerte del pensamiento mesoamericano, queda claro que la religión católica no ha permeado en los cimientos de las concepciones ancestrales. El hecho de que la iglesia católica tenga presencia en la comunidad de Tepoxteco no ha sido un impedimento para que estas prácticas rituales se sigan llevando a cabo. La implementación tardía de la instrucción católica, iniciada a finales de 1979, y la ausencia de un propio santo en la comunidad de Tepoxteco cuyos miembros tampoco peregrinan a otra localidad asociada con un santo católico, son factores bastante importantes que contribuyen a la conservación de la tradición indígena. Los habitantes peregrinan únicamente para visitar a sus deidades, sobre todo en el Cerro Postectitlan. Solamente unas pocas familias de Tepoxteco se identifican con la iglesia católica, mientras que la mayoría ha optado por continuar con sus costumbres y tradiciones, una cultura milenaria. Considerando todas estas manifestaciones arraigadas profundamente en el pensamiento nahua, podemos afirmar que lo que López Austin describe como la tradición religiosa mesoamericana ${ }^{41}$ está muy presente entre los nahuas de Tepoxteco.

\section{AGRADECIMIENTOS}

Agradezco a los habitantes de la comunidad nahua de Tepoxteco, Chicontepec, Veracruz por permitirme escribir sobre su cultura así como a Justyna Olko y a John Sullivan por sus valiosos comentarios a este trabajo.

\section{BIBLIOGRAFÍA}

Báez-Jorge F., Gómez Martínez A., 'Los equilibrios del cielo y de la tierra. Cosmovisión de los nahuas de Chicontepec', Desacatos, Núm. 5 (2000).

Bernardino de Sahagún, The Florentine Codex. General History of the Things of New Spain, trad. Ch.E. Dibble, A.J.O. Anderson, pt. 3. Book 2: The Ceremonies, Santa Fe 1970 (Monographs of the School of American Research, 14).

Bernardino de Sahagún, Primeros Memoriales, trad. T.D. Sullivan, H.B. Nicholson, Norman 1997 (Civilization of the American Indian Series, v. 200, pt. 2).

Bierhorst J., A Nahuatl-English Dictionary and Concordance to the Cantares Mexicanos, with an Analytic Transcription and Grammatical Notes, Stanford 1985.

Durán D., Historia de las Indias de Nueva España e islas de Tierra Firme, ed. A.M. Garibay K., Vol. 1, México 1984 (Biblioteca Porrúa).

Grigsby T.L., Cook de Leonard C., 'Xilonen in Tepoztlán: A Comparison of Tepoztecan and Aztec Agrarian Ritual Schedules', Ethnohistory, Vol. 39, Núm. 2 (1992), en <http://dx.doi. org/10.2307/482390>.

41 A. López Austin, Tamoanchan y Tlalocan..., p. 10-17. 
Lockhart J., Los nahuas después de la conquista. Historia social y cultural de la población indígena del México central, siglos XVI-XVIII, trad. R. Reyes Mazzoni, México 1999 (Sección de Obras de Historia).

López Austin A., Cuerpo humano e ideología. Las concepciones de los antiguos nabuas, México 1996 (Serie Antropológica, 39).

López Austin A., Tamoanchan y Tlalocan, México 1994 (Sección de Obras de Antropología).

Nicholson H.B., 'Religion in Pre-hispanic Central México' en R. Wauchope, G.F. Ekholm, I. Bernal (ed.), Handbook of Middle American Indians, Vol. 10: Archeology of Northern Mesoamerica, pt. 1, Austin 1971.

Olko J., 'Hierogamy in the Aztec Ritual', Estudios Latinoamericanos, Vol. 19 (1999).

Sandstrom A.R., El maiz es nuestra sangre. Cultura e identidad etnica de un pueblo indio azteca contemporáneo, trad. SA Piotrowska, W.H. Klemme, D.L. Oberstar, México 2010 (Colección Huasteca).

Taube K., 'The Classic Maya Maize God: A Reappraisal' en V.M. Fields, M.G. Robertson (coord.), Fifth Palenque Round Table 1983. Proceedings of the Fifth Palenque Round Table Conference, June 12-18, 1983, Palenque, Chiapas, Mexico, Vol. 3, San Francisco 1985.

Victoriano de la CRUZ CRUZ, M.A. - a native speaker and linguist of the Nahuatl language, was born in Tepoxteco, Chicontepec, Veracruz. He has a master's degree in Indoamerican Linguistics from the Centro de Investigaciones y Estudios Superiores en Antropología Social (CIESAS) in Mexico City. Between 2012 and 2015 he worked as a researcher in the Faculty of "Artes Liberales" at the University of Warsaw participating in the projects "Language Encounters between the Old and New Worlds" (Focus Program, Foundation for Polish Science) and "Europe and America in contact: a multidisciplinary study of cross-cultural transfer in the New World across time" financed by the European Research Council. His areas of interest include language contact, Nahuatl syntax and morphology, and the Nahua worldview as reflected in the language. He worked at the Instituto de Docencia e Investigación Etnológica de Zacatecas between 2003 and 2012, and served as the assistant director of research at the Instituto Nacional de Lenguas Indígenas in Mexico in 2012. 